\title{
Adult-onset chronic progressive external ophthalmoplegia with mitochondrial myopathy
}

INSERM

\section{Source}

INSERM. (1999). Orphanet: an online rare disease and orphan drug data base. Adultonset chronic progressive external ophthalmoplegia with mitochondrial myopathy. ORPHA:329336

Adult-onset chronic progressive external ophthalmoplegia with mitochondrial myopathy is a rare mitochondrial disease characterized by adult onset of progressive external ophthalmoplegia, exercise intolerance, muscle weakness, manifestations of spinocerebellar ataxia (e.g. impaired gait, dysarthria) and mild motor peripheral neuropathy. Respiratory insufficiency has been reported in some cases. 